\title{
Psychological and Demographic Determinants of Substance Use and Mental Health During the COVID-19 Pandemic
}

\author{
Fatima Mougharbel ${ }^{1,2}$, Hugues Sampasa-Kanyinga ${ }^{2,3}$, Brandon Heidinger ${ }^{2}$, \\ Kim Corace ${ }^{4,5,6}$, Hayley A. Hamilton ${ }^{7,8,9}$ and Gary S. Goldfield ${ }^{2,10 *}$
}

${ }^{1}$ Interdisciplinary School of Health Sciences, University of Ottawa, Ottawa, ON, Canada, ${ }^{2}$ Healthy Active Living and Obesity Research Group, Children's Hospital of Eastern Ontario Research Institute, Ottawa, ON, Canada, ${ }^{3}$ School of Epidemiology and Public Health, University of Ottawa, Ottawa, ON, Canada, ${ }^{4}$ The Royal's Institute of Mental Health Research, Ottawa, ON, Canada, ${ }^{5}$ Faculty of Medicine, University of Ottawa, Ottawa, ON, Canada, ${ }^{6}$ The Royal Ottawa Mental Health Centre, Ottawa, ON, Canada, ${ }^{7}$ Centre for Addiction and Mental Health, Institute for Mental Health Policy Research, Toronto, ON, Canada, ${ }^{8}$ Centre for Addiction and Mental Health, Campbell Family Mental Health Research Institute, Toronto, ON, Canada, ${ }^{9}$ Dalla Lana School of Public Health, University of Toronto, Toronto, ON, Canada, ${ }^{10}$ Department of Pediatrics, University of Ottawa, Ottawa, ON, Canada

OPEN ACCESS

Edited by:

Paolo Roma,

Sapienza University of Rome, Italy

Reviewed by:

Kathryn Sabella,

University of Massachusetts Medical

School, United States

Basema Saddik,

University of Sharjah, United

Arab Emirates

*Correspondence:

Gary S. Goldfield

ggoldfield@cheo.on.ca

Specialty section:

This article was submitted to

Public Mental Health,

a section of the journal

Frontiers in Public Health

Received: 12 March 2021

Accepted: 27 May 2021

Published: 25 June 2021

Citation:

Mougharbel F, Sampasa-Kanyinga $H$, Heidinger $B$, Corace $K$, Hamilton $H A$ and Goldfield GS (2021) Psychological and Demographic Determinants of Substance Use and Mental Health During the COVID-19 Pandemic

Front. Public Health 9:680028. doi: 10.3389/fpubh.2021.680028
Background: Alcohol consumption and distress have increased among Canadians since the start of the COVID-19 pandemic.

Methods: We examined whether sociodemographic and COVID-19-related worries are associated with various combinations of alcohol consumption and comorbid psychological distress variables among a Canadian sample of adults. Data were derived from a sample of Canadian adults ( $N=1,005,49.6 \%$ female) who participated in an online survey in May 2020. Four multivariate ordinal logistic regression models were used to estimate the odds of binge drinking, increased alcohol consumption during the pandemic, and psychological distress. Predictor variables used in the analyses included self-reported sociodemographic characteristics, financial worries, COVID-19 impact on work, and worrying about getting ill.

Results: Women were found to have higher odds of increased drinking and anxiety. Also being divorced, separated, or widowed was associated with higher odds of binge drinking and anxiety, and binge drinking and depression. Furthermore, being 60 or older was associated with lower odds of binge drinking and depression and increased drinking and depression, as well as lower odds of increased drinking and depression and increased drinking and anxiety. High income groups were associated with higher odds of binge drinking, increased drinking, and mental distress. Compared to those less worried, being very worried about finances were associated with higher odds of binge drinking and anxiety, increased drinking and anxiety, and increased drinking and depression. Also, being very worried about getting ill with COVID was associated with higher odds of binge drinking and anxiety and increased drinking and anxiety.

Conclusion: Our findings identify several demographic and COVID-related worries for increased odds of alcohol intake and co-morbid psychological distress during the 
COVID-19 pandemic, including identifying as a woman, high income groups, being divorced, separated or widowed, and experiencing financial worries and COVID illness worries. These characteristics should be considered when developing prevention and treatment programs for adults with problematic alcohol use and comorbid anxiety and depression.

Keywords: alcohol use and alcohol problems, binge drinking, anxiety, depression, concurrency, COVID-19

\section{BACKGROUND}

At the beginning of Spring 2020, the coronavirus disease 2019 (COVID-19) hit many countries globally, including Canada. This led the federal and provincial authorities to implement stringent measures to limit the virus' spread and flatten the curve. These measures included closures of schools, non-essential businesses, and community centers, resulting in most of the population being confined to their homes. Upon a phased reopening, strict physical distancing measures were implemented, resulting in diminished frequency and quality of social interactions (1).

In no time in recent human history have individuals been subjected to such social and occupational restrictions, making the current COVID-19 environment uniquely stressful. The COVID19 pandemic, similar to other pandemics, placed individuals at an increased risk for developing (or exacerbating) anxiety, depression, and problematic substance use as the demands of coping with the pandemic may outweigh perceived emotional and financial resources to cope (2). Indeed, recent studies linked this pandemic and its associated consequences with increased rates of depression and anxiety (3-6). For example, a survey conducted during the COVID-19 pandemic (June 2020) among 5,470 adults in the USA showed that the percentage reporting symptoms of anxiety was three times higher than what was reported in 2019 (25.5 vs. 8.1\%), and the percentage reporting symptoms of depression was about four times higher than in 2019 (24.3 vs. $6.5 \%)$ (3).

Several studies have examined substance use, such as alcohol consumption, during the COVID-19 pandemic (7-9). A recent study in the USA (9) among 1,540 adults examined changes in alcohol consumption from before to during the COVID-19 pandemic through the number of days of alcohol use and binge drinking over the past 30 days. This study showed an increase of $14 \%$ in the frequency of alcohol consumption, and an increase of $19 \%$ in binge drinking during the pandemic. Interestingly, women in this study showed a significant increase of $41 \%$ in binge drinking during the pandemic. A Canadian survey of 1,009 adults found that one in five Canadians who stayed at home more during the pandemic reported an increase in both quantity and frequency of alcohol consumption. Boredom, stress and changes in routine were among the strongest contributing factors for increased alcohol consumption reported in this survey (7).

Increases in alcohol consumption and binge drinking, relative to pre-pandemic levels, could be due to many factors including a maladaptive way of coping with stress and anxiety (i.e., self-medicating) $(10,11)$. Additionally, this pandemic has increased feelings of social isolation and loneliness, which are well-known to increase the risk of problematic alcohol consumption (12-14). This is concerning because alcohol can suppress immune function $(15,16)$, consequently leaving individuals more vulnerable to COVID-19, respiratory illnesses (16), systemic inflammation $(17,18)$, and a range of other disease states that can lead to hospitalization (19). Moreover, problematic alcohol use increases the risk of metabolic disorders (20), cardiovascular disease (21-23), neurocognitive disorders (24), mental illness (25), and all cause mortality (26).

Although, the determinants of anxiety, depression, and problematic substance use are each widely studied, less attention has been paid to the factors associated with experiencing both mental health and substance use problems at the same time, a phenomenon known as concurrency. It can also be called, dual diagnosis, dual disorders, or co-occurring substance use and mental health problems (27). Previous data indicated an association between concurrent disorders and high costs of care, and increased morbidity and mortality rate (28-30). People with concurrency experience poorer physical (31) and mental health (32) than individuals with a single problem. They also have higher use of medical and psychological health services which place a high economic burden on the health care system (29, 33-35).

The high prevalence and personal and economic costs of concurrency highlight a crucial need for a better understanding of its determinants, and this is especially important during the pandemic to inform the development of effective treatment and prevention strategies. The relationship between the two concurrent conditions is complex (36) and factors that contribute to this complexity can include demographic and individual factors, but it also can be social-cultural in nature $(8,37)$. While some studies examined the impact of the COVID-19 pandemic on mental health and aspects of substance use such as substance use disorders (38) and the impact of this association on suicide (39), no studies, to our knowledge have investigated the determinants of concurrency during the pandemic. In addition, factors relating to the social determinants of health such as marital status, socio-economic status, changes to employment status, or being a parent of young children have not yet been examined.

Accordingly, the purpose of this study was to examine the association between socio-demographic, and COVID-19 related worries and combinations of concurrent alcohol use, depression, and anxiety in a sample of Canadian adults during the COVID-19 pandemic. 


\section{METHODS}

\section{Study Sample}

This study performed a secondary data analysis based on data from a survey conducted by the Centre for Addiction and Mental Health in collaboration with Delvinia, a research technology and market survey company. An English-speaking Canadian adult sample $(N=1,005)$ completed an online survey in the early part of the pandemic from May 8 to 12, 2020, through an automated web-based panel which links organizations to real people to obtain data (http://www.delvinia.com/solutions/ askingcanadians/, accessed August 18, 2020). Participants were sourced from the AskingCanadians web panel (http://corporate. askingcanadians.com/) of over 1 million Canadians hosted by Delvinia (data are publicly available: http://www.delvinia.com/ camh-coronavirus-mental-health/). Respondents were recruited on the basis of loyalty collaborations with retailers, departmental stores, and airlines. The study was approved by the Research Ethics Board at the Centre for Addiction and Mental Health. Also, this study has been reviewed by the Research Ethics Boards of the Children's Hospital of Eastern Ontario (CHEO). Participation was voluntary, and all participants provided their consent electronically. Quota sampling was utilized such that the sample of 1,005 adult respondents reflected the distribution of English-speaking Canadians by gender, age, and geographic region (British Columbia, Alberta, Saskatchewan/Manitoba, Ontario, Quebec/Atlantic provinces, and the territories including Yukon, Nunavut, and the Northwest Territories).

\section{Distress Variables Measures Depressive Symptoms}

Depressive symptoms were assessed using a 3-item short form of the Center for Epidemiologic Studies Depression Scale (CESD) (40). The 3-item scale asks participants how frequently they felt depressed, lonely, or hopeful about the future over the past 7 days. Items were scored using a 4-point Likert-type frequency scale from " $1=$ Rarely or none of the time ( $<1$ day)" to " 4 $=$ Most or all of the time (5-7 days)." The item on feeling hopeful was reverse scored, so higher scores reflect less hope about the future. A composite score was calculated, with raw scores ranging from 3 to 12 . For data analyses, participants who scored $\geq 10$ were classified as having higher severity of symptoms, while participants scoring $<10$ were considered to be less symptomatic (40).

\section{Anxiety}

Anxiety was measured using the Generalized Anxiety Disorder (GAD-7) scale (41). This is a self-report measure that includes seven items; for each one, participants were asked to rate the frequency in which they experienced anxiety symptoms over the last 2 weeks on a Likert-type frequency scale from $0=$ "Not at all" to 3 = "Nearly every day" (41). A composite score was calculated, with raw scores ranging from 0 to 21 . Individuals who scored 0-9 were considered as having no to mild anxiety symptoms, and those who scored $\geq 10$ were classified as having symptoms of moderate to severe anxiety (42).

\section{Substance Use Measures Increased Drinking}

Increased alcohol consumption was measured using the following item: "In the PAST 7 DAYS, did you drink more ALCOHOL, about the same, or less alcohol overall than you did before the COVID-19 pandemic started?" Response options were coded 1 = "Drink much more alcohol," 2 = "Drink slightly more alcohol," 3 = "No change," 4 = "Drink slightly less alcohol," $5=$ "Drink much less alcohol." A dichotomous measure was created to reflect increased alcohol consumption (drink much more or slightly more alcohol) or not. Individuals who did not report consuming alcohol in the past week were coded as no increase in use.

\section{Binge Drinking}

Binge drinking was assessed by the item: "how many of the PAST 7 DAYS did you drink [four (if woman) or five (if man) or five (if another gender)] or more drinks on one occasion? A drink means $341 \mathrm{ml}$ or $12 \mathrm{oz}$. bottle of beer or cider/cooler (5\% alcohol content), a $142 \mathrm{ml}$ or $5 \mathrm{oz}$. glass of wine (12\% alcohol content), or a straight or mixed drink with $43 \mathrm{ml}$ or $1.5 \mathrm{oz}$. of liquor (40\% alcohol content - e.g., rye, gin, rum).” Response options ranged from 0 to 7 days. In the data analysis, binge drinking was operationally defined as consuming five or more drinks per episode for men and as four or more drinks per episode for women. This was coded dichotomously as binge drinking (1) or not (0). Individuals who did not report consuming alcohol in the past week were coded as not binge drinking.

\section{Dependent Variables - Increased Alcohol Consumption and Distress (Concurrency Variables)}

Risk variables were created using the following combinations of both distress and problematic drinking variables: (1) binge drinking and anxiety, (2) binge drinking and depression, (3) increased drinking and anxiety, (4) increased drinking and depression. Risk items were coded from 0 to 2 with $0=$ no risk and $2=2$ risks for each combination of mental distress and alcohol use variables.

\section{Independent Variables - COVID-19 Relevant Factors}

For COVID-19 illness worries and financial worries, participants were asked the following questions: (1) Whether they are worried that they or someone close to them will get ill from COVID-19? (2) Whether they are worried about the impact of COVID-19 on their personal financial situation? Responses included ( $1=$ very worried; $2=$ somewhat worried; $3=$ not very worried; $4=$ not at all worried). COVID-19 illness worries, and financial worries variables were coded from 0 to 3 after reversing the scoring $(0$ $=$ not very or not at all worried; $1=$ somewhat worried; $2=$ very worried).

\section{Sociodemographic Factors}

Sociodemographic measures consisted of the following variables including how they were coded in the analysis:

Gender $(1=$ man, $2=$ woman, $3=$ other $)$; age $(1=$ $18-39,2=40-59,3=60+$ years $)$, marital status $(1=$ married or living with a partner; $2=$ divorced, separated, or 
widowed; $3=$ never married), education ( $1=$ not completed high school; 2 = completed high school; completed some postsecondary graduation; $3=$ completed college or university education), number of children aged 6-12 years at home, and household income $(1=<\$ 40,000 ; 2=\$ 40,000-\$ 79,000$; $3=\$ 80,000-\$ 119,000 ; 4=\$ 120,000$ or more). Ethnicity included (Asian - East; Asian - South; Asian - southeast; Black; Indigenous; Latin American; Middle Eastern; White; Mixed heritage; Other), we dichotomized this variable as the following $(0=$ white; $1=$ other $)$.

\section{Statistical Analysis}

Analyses were done within SPSS (version 26) and Stata 14.1 (Stata Corporation, College Station, TX, USA). Descriptive analysis was used to describe the sample. Correlations were calculated to assess relations and directionality between independent variables (age, gender, marital status, education, number of children, income, ethnicity, financial worries, COVID-19 illness worries, and COVID-19 impact on working hours) and primary dependent variables (binge drinking and anxiety, binge drinking and depression, increase drinking and anxiety, increase drinking and depression). Multivariate ordinal logistic regression was performed for all candidate predictor variables to examine their associations with co-occurrence of (1) binge drinking and anxiety, (2) binge drinking and depression, (3) increase drinking and anxiety, and (4) increase drinking and depression. Odds ratios (OR) and $95 \%$ confidence intervals (CI) for fully adjusted models are presented.

\section{RESULTS}

\section{Demographics and Characteristics of the Study Variables}

Table 1 presents the characteristics of the full sample for all variables of interest. Seventy-one percent of the study sample was comprised of white participants. Approximately $61.8 \%$ of the participants were married or living with a partner, $9.1 \%$ had at least one child aged 6-12 years, and $72.9 \%$ had completed college/university. Furthermore, most of the study participants (77.2\%) were worried about them or someone close to them getting ill from COVID-19, and $69.2 \%$ of participants had financial worries.

Furthermore, $7.5 \%$ of participants had elevated depressive symptoms and $25.5 \%$ experienced moderate to severe anxiety. Furthermore, $23.7 \%$ reported binge drinking and $25.2 \%$ reported an increase in alcohol consumption. Concurrency variables indicated that higher percentages of respondents reported binge drinking and anxiety $(9.7 \%)$ and increased drinking with anxiety (10\%) compared to binge drinking and depression (2.2\%) and increased drinking and depression (2.5\%).

Bivariate correlations for all variables of interest are shown in Table 2. Age was inversely correlated with binge drinking and anxiety $(\mathrm{r}=-0.20, p<0.01)$, and binge drinking and depression $(\mathrm{r}=-0.16, p<0.01)$, as well as increased drinking and anxiety $(\mathrm{r}=-0.16, p<0.01)$, and increased drinking and depression $(\mathrm{r}$ $=-0.11, p<0.01)$.
TABLE 1 | Descriptive characteristics of the study variables.

Frequency Valid percent

Gender $(n=1,002)$
Male

Female

Other

Age $(n=1,005)$

18-39 years

$40-59$ years

$60^{+}$years

Ethnicity $(n=985)$

White

Others

Income $(n=839)$

$<40 \mathrm{k}$

$40-79 \mathrm{k}$

$80-119 \mathrm{k}$

$120 \mathrm{~K}^{+}$

504

498

3

394

306

305

698

287

128

268

226

217

Education ( $n=998)$

Not completed high school

High school/some level of post-secondary school

College or University graduate

Number of children/young children (6-12) $(n=1,005)$ 0

1

2

3

Marital status $(n=992)$

Married or living with a partner

Divorced, separated, or widowed

Not married

COVID illness worries $(n=1,005)$

Not very/not at all worried

Somewhat worried

Very worried

Financial worries $(n=1,005)$

Not very/not at all worried

Somewhat worried

Very worried

Depression scores $(n=1,005)$

No depression to mild depression (3-9)

Moderately severe depression (10-12)

Anxiety score $(n=1,005)$

No to mild anxiety (0-9)

Moderate to severe anxiety (10-21)

Binge drinking $(n=1,003)$

Yes

No

Increase drinking $(n=1,005)$

Yes

No

Binge drinking and Anxietya $(n=1,003)$

0

606 
TABLE 1 | Continued

\begin{tabular}{lcc}
\hline & Frequency & Valid percent \\
\hline 1 & 300 & $29.9 \%$ \\
2 & 97 & $9.7 \%$ \\
Binge drinking and depression $(n=1,003)$ & & \\
0 & 712 & $71 \%$ \\
1 & 269 & $26.8 \%$ \\
2 & 22 & $2.2 \%$ \\
Increase drinking and anxiety $(n=1,005)$ & & \\
0 & 595 & $59.2 \%$ \\
1 & 311 & $30.8 \%$ \\
2 & 99 & $10 \%$ \\
Increase drinking and depression $(n=1,005)$ & & \\
0 & 703 & $70.0 \%$ \\
1 & 276 & $27.5 \%$ \\
2 & 26 & $2.5 \%$
\end{tabular}

Outcome variables were coded from 0 to 2 with $0=$ no risk; $1=$ risk for either mental distress or alcohol consumption; and 2 = 2 risks for each combination of mental distress and alcohol use variables.

Being a woman was correlated with increased drinking and anxiety $(\mathrm{r}=0.10, p<0.01)$, and increased drinking and depression $(r=0.10, p<0.05)$. Income was positively correlated with increased drinking and anxiety $(\mathrm{r}=0.10, p<0.01)$ and increased drinking and depression $(\mathrm{r}=0.10, p<0.05)$. Having elementary school age children 6-12 years was positively associated with binge drinking and anxiety $(\mathrm{r}=0.10, p<$ $0.05)$ and binge drinking and depression $(r=0.10, p<0.05)$, but not increased drinking and distress. Furthermore, being divorced, separated, or widowed was positively associated with binge drinking and depression $(r=0.10, p<0.05)$. Worrying about getting ill from COVID-19 was positively associated with binge drinking and anxiety $(\mathrm{r}=0.25, p<0.01)$, and binge drinking and depression $(\mathrm{r}=0.13, p<0.01)$, and increased drinking and anxiety $(\mathrm{r}=0.22, p<0.01)$, and depression as well $(\mathrm{r}=0.10, p<0.05)$. Moreover, financial worrying was positively associated with binge drinking and anxiety, and depression $(\mathrm{r}=$ $0.30, p<0.01)$ and binge drinking and depression $(\mathrm{r}=0.14, p<$ $0.01)$, as well as increased drinking and anxiety ( $\mathrm{r}=0.24, p<$ 0.01 ), and increased drinking and depression $r=0.10, p<0.05)$.

\section{Multivariate Ordinal Regression Modeling of Effects of COVID-19 Risk Factors on Binge Drinking and Increased Drinking and Mental Distress}

Results of multivariate ordinal regression analysis examining the association between combinations of distress and alcohol use variables are summarized in Table 3. Results indicate that being older in age was associated with lower odds of binge drinking and anxiety (OR 0.33, 95\% CI, 0.22-0.49), and binge drinking and depression (OR 0.39, 95\% CI, 0.25-0.61), as well as lower odds of increased drinking and anxiety (OR 0.44, 95\% CI, 0.30-0.65), and increased drinking and depression
(OR 0.56, 95\% CI, 0.37-0.85). In addition to that, identifying as woman was significantly associated with greater odds of increased drinking and anxiety (OR 1.36, 95\% CI, 1.03-1.80). Also, being divorced, separated, or widowed was associated with higher odds of binge drinking and anxiety (OR 1.74; 95\% CI 1.03-2.92) and binge drinking and depression (OR 1.87; 95\% CI 1.10-3.21).

Furthermore, higher income groups were associated with higher odds of increased drinking and anxiety (OR 2.12; 95\% CI, 1.29-3.49), and increased drinking and depression (OR 2.38; 95\% CI, 1.37-4.14) compared to low-income groups. In addition to that, experiencing a lot of financial worries was associated with significantly higher odds of binge drinking and anxiety (OR 3.09; 95\% CI, 1.97-4.85), and binge drinking and depression (OR 1.81; $95 \% \mathrm{CI}, 1.12-2.94)$ as well as increased drinking and anxiety (OR 2.58; 95\% CI, 1.66-4.00) compared to not being worried. Also, being very worried about getting ill from COVID-19 was associated higher odds of binge drinking and anxiety (OR 2.65; 95\% CI, 1.68-4.16), and increased drinking and anxiety (OR 2.36; 95\% CI, 1.52-3.69) compared to not being worried about COVID-19 illness.

\section{DISCUSSION}

To our knowledge, this study is the first to examine factors influencing the concurrency of alcohol use and mental health in a Canadian population of adults during the COVID-19 pandemic. Our study identified several sociodemographic, and COVID-19 related worries that were associated with concurrency. Being older in age (60 years and more) was associated with higher odds of binge drinking and distress and increased drinking and distress symptoms. Also, being a woman was associated with higher odds of increased drinking and anxiety. Being divorced, separated, or widowed was also associated with both binge drinking and anxiety and binge drinking and depression. High income was associated with higher odds of binge drinking and anxiety and binge drinking and depression. In addition to that, those who were very worried financially and were very worried about getting COVID-19 illness were more likely to consume alcohol and experience more mental health issues compared to those who worry less, in a dose-response gradient.

As the present study contributed to the literature with an aim to examine COVID-19 factors on symptoms of concurrency, drawing on previous literature examining the pandemic's impact on alcohol consumption and mental health issues separately is informative $(9,43,44)$. For example, our study found that that $25.2 \%$ of the total sample reported increased alcohol intake during COVID, which is somewhat consistent with the $19 \%$ reported from an epidemiological sample of American adults during the pandemic (9), and with the Canadian Centre on Substance Use and Addiction survey which indicated a $20 \%$ increase in alcohol consumption among staying at home Canadians because of the pandemic (7). Additionally, our findings indicate that $33 \%$ reported elevated symptoms of anxiety or depression during the pandemic, consistent with a recent meta-analytic review showing a heightened 
TABLE 2 | Spearman correlations between all main study variables.

\begin{tabular}{|c|c|c|c|c|c|c|c|c|c|c|c|c|c|c|c|c|c|}
\hline & 1. & 2. & 3. & 4. & 5. & 6. & 7. & 8. & 9. & 10. & 11. & 12. & 13. & 14. & 15. & 16. & 17. \\
\hline 1. Age & - & & & & & & & & & & & & & & & & \\
\hline 2. Gender & 0.008 & - & & & & & & & & & & & & & & & \\
\hline 3. Ethnicity & $-0.283^{\star \star}$ & $-0.091^{\star \star}$ & - & & & & & & & & & & & & & & \\
\hline 4. Income & $-0.109^{\star \star}$ & -0.070 & 0.010 & - & & & & & & & & & & & & & \\
\hline 5. Education & $-0.118^{\star \star}$ & -0.040 & $0.097^{\star \star}$ & $0.220^{\star *}$ & - & & & & & & & & & & & & \\
\hline 6. Having young children (6-12) & $-0.127^{\star \star}$ & 0.006 & $0.088^{\star *}$ & 0.051 & 0.045 & - & & & & & & & & & & & \\
\hline 7. Marital status & $-0.216^{\star \star}$ & 0.041 & $0.084^{\star \star}$ & $-0.315^{\star \star}$ & $-0.100^{\star \star}$ & $-0.120^{\star \star}$ & - & & & & & & & & & & \\
\hline 8. Covid illness worries & 0.059 & $0.123^{\star \star}$ & $-0.180^{\star \star}$ & -0.031 & $0.080^{*}$ & 0.050 & -0.040 & - & & & & & & & & & \\
\hline 9. Financial worries & $-0.066^{\star}$ & $0.064^{\star}$ & $0.190^{* \star}$ & $-0.100^{\star \star}$ & $0.070^{*}$ & 0.050 & 0.010 & $0.450^{\star *}$ & - & & & & & & & & \\
\hline 10. Moderate to severe anxiety & $-0.137^{\star \star}$ & $0.100^{\star *}$ & $0.100^{* \star}$ & -0.031 & -0.033 & 0.054 & 0.008 & $0.324^{* *}$ & $0.352^{* \star}$ & - & & & & & & & \\
\hline 11. Moderate to severe depression & -0.048 & $0.104^{\star \star}$ & -0.002 & $-0.126^{\star}$ & -0.041 & $0.100^{*}$ & $0.121^{\star \star}$ & $0.140^{\star \star}$ & $0.160^{* *}$ & $0.400^{\star *}$ & - & & & & & & \\
\hline 12. Binge drinking & $-0.158^{\star \star}$ & $-0.100^{\star \star}$ & 0.052 & $0.080^{*}$ & -0.041 & $0.100^{*}$ & 0.012 & $0.070^{*}$ & $0.080^{*}$ & $0.200^{\star \star}$ & 0.037 & - & & & & & \\
\hline 13. Increase drinking & $-0.112^{\star}$ & 0.029 & -0.042 & $0.172^{*}$ & 0.050 & 0.040 & -0.042 & 0.020 & 0.019 & $0.182^{\star \star}$ & $0.062^{\star}$ & $0.475^{\star \star}$ & - & & & & \\
\hline 14. Binge drinking and Anxiety & $-0.200^{\star \star}$ & 0.009 & 0.100 & 0.033 & -0.051 & $0.100^{*}$ & 0.008 & $0.253^{\star \star}$ & $0.300^{* \star}$ & $0.770^{\star \star}$ & $0.287^{\star \star}$ & $0.745^{\star \star}$ & $0.387^{\star \star}$ & - & & & \\
\hline 15. Binge drinking and depression & $-0.162^{\star \star}$ & -0.026 & 0.043 & 0.007 & -0.051 & $0.100^{*}$ & $0.080^{*}$ & $0.130^{\star \star}$ & $0.144^{\star \star}$ & $0.350^{\star *}$ & $0.482^{\star *}$ & $0.875^{\star \star}$ & $0.429^{\star \star}$ & $0.800^{\star *}$ & - & & \\
\hline 16. Increase drinking and anxiety & $-0.163^{\star \star}$ & $0.100^{* *}$ & 0.040 & $0.100^{\star *}$ & 0.012 & 0.053 & -0.020 & $0.224^{\star \star}$ & $0.240^{* *}$ & $0.756^{\star \star}$ & $0.300^{\star *}$ & $0.400^{\star *}$ & $0.752^{\star *}$ & $0.743^{* *}$ & $0.500^{* *}$ & - & \\
\hline 17. Increase drinking and depression & $-0.117^{\star \star}$ & $0.100^{*}$ & -0.042 & $0.100^{*}$ & 0.031 & 0.052 & 0.024 & $0.100^{*}$ & $0.100^{*}$ & $0.322^{\star \star}$ & $0.480^{\star \star}$ & $0.419^{\star \star}$ & $0.900^{* *}$ & $0.460^{* *}$ & $0.600^{\star *}$ & $0.800^{\star *}$ & - \\
\hline
\end{tabular}

${ }^{*} p<0.05,{ }^{* *} p<0.01$. Gender (male/female), ethnicity (white/non-white), income (<40,000, 40,000-79,000, 80,000-120,000, >120,000 and more), education (less than high school; completed high school or some post-secondary graduation; college or university), marital status (married or living with a partner; widowed, divorced, separated; or never married), COVID illness worries (not very or not al all worried; somewhat worried; very worried); COVID financial worries (not very or not al all worried; somewhat worried; very worried). 
TABLE 3 | Multivariate analysis for the associations between all predictor variables and binge drinking and anxiety; binge drinking and depression; increase drinking and anxiety; and increase drinking and depression.

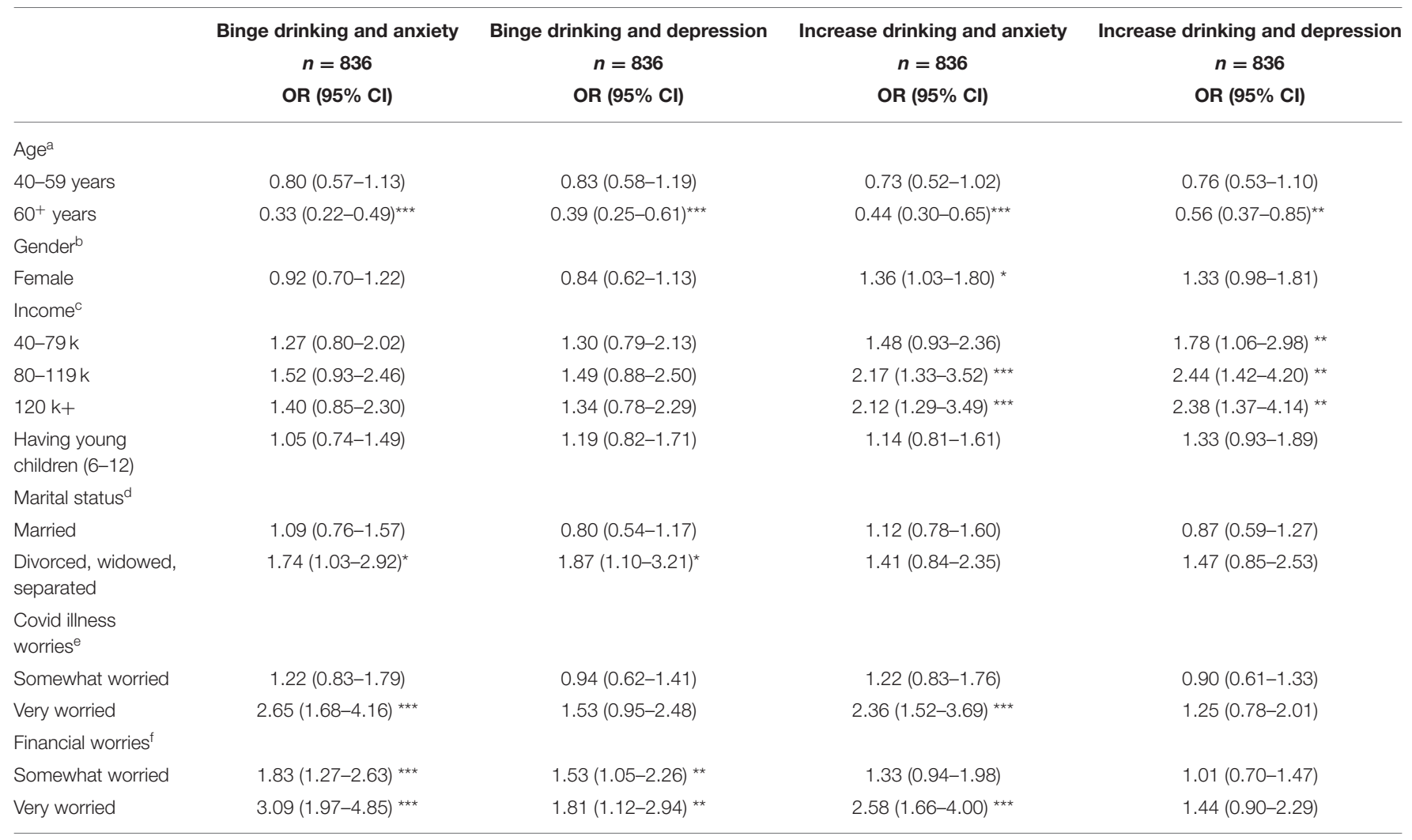

OR, odds ratio; $\mathrm{Cl}$, confidence interval. ${ }^{*} p<0.05 ;{ }^{* \star} p<0.01 ;{ }^{* \star *} p<0.001$. Reference categories: ${ }^{a} 18-39$ years; ${ }^{b}$ male; ${ }^{c}<40 \mathrm{k}^{\circ}{ }^{d}$ Never married; ${ }^{e}$ not at all worried; ${ }^{f}$ not at all worried.

prevalence of psychological problems in association with the COVID-19 pandemic (44).

While previous studies have focused on either mental health or substance use during the pandemic, our study has more specifically examined risk factors for the concurrency of alcohol use and elevated symptoms of anxiety and depression in adults. We found that those who are very worried about the impact of COVID-19 on their finances were more likely to binge or increase drinking and experience feelings of depression and/or anxiety. This would suggest that financial stress related to possibly losing their job or possibly to reduced work hours may lead to increased alcohol intake and heightened distress, perhaps due to maladaptive coping skills. This study also found that being very worried about getting ill from COVID-19 was also associated with higher odds of binge drinking and anxiety, and increased drinking and anxiety compared to those who were less worried. These findings are in line with previous studies examining stress and drinking showing that elevated stress may be associated with increased alcohol consumption $(45,46)$ as a maladaptive approach to cope with stress and worry.

Moreover, individuals with higher income were more likely to consume alcohol and suffer from mental distress. However, our bivariate analysis indicates that higher income is associated with increased drinking but not mental distress. Thus, income may be a predictor of concurrency more because of boredom and access and not as a coping mechanism for anxiety as higher income individuals are less worried financially and their distress levels are lower. This aligns with previous studies which indicated that people with a higher income reported consuming more alcohol during the pandemic than those of the lower income (47-51). This finding is consistent with behavior economics theory, an approach that explores conditions and factors influencing the consumption of commodities $(52,53)$ including alcohol intake (54), although, concurrent mental illness has not been examined in these models. According to this approach, more affordability, and few restrictions to access to substances are among the strongest predictors of consumption (54). Thus, limitations in affordability, in turn, limit access to alcohol consumption, which may explain the lower odds of alcohol consumption among lower income groups compared to higher incomes who experienced less financial worries and might have more disposable income.

Our study also showed that older adults were at lower odds of increased alcohol consumption and comorbid psychological distress, consistent with recent literature which examined the impact of COVID-19 relevant factors on mental health, and/or substance use separately $(3,55-57)$. Canadians 60 years of 
age and older were less likely to experience concurrency symptoms compared to Canadians 40-59, and 18-39 years. These associations may be attributed to older adults being better able to cope and be more resilient in crisis due to biological stress response, personality attributes, life experience, as well as a better financial stability, social and economic status (58). Furthermore, getting older is associated with enhanced life experience, which may enhance emotional regulation and self compassion, and higher spiritual components of wisdom (59) which can help in coping with crisis.

Our findings showed that identifying as woman was associated with increased odds of increased alcohol and anxiety.

This aligns with previous studies which indicated that women were more likely to experience stress, anxiety and depressive symptoms during the pandemic than men $(43,60$, 61). Furthermore, evidence indicated that alcohol consumption increased during the pandemic among women $(50,62)$. The lockdown added a lot of mental burden on women $(60,63,64)$. This can be due to increased demands in a caregiving role, household and family responsibilities, and gender inequalities in work (64-66). Accordingly, to cope with mental distress, women may tend to increase their alcohol consumption (7, 67-69). This trend is unfortunately not recent. Previous data confirm that even though women usually drink less than men, gender gap in alcohol consumption is getting narrower over time $(70,71)$. Alcohol consumption as a coping mechanism with distress was more relevant to women's than men's drinking, especially in the past decades where women's roles have increased with more employment opportunities, and family responsibilities (71-73). Marital status seems to be a significant feature of concurrency symptoms. Being divorced, separated, or widowed compared to married people was associated with higher odds of binge drinking and distress, findings that align with previous literature $(43,61,74-76)$. It has been indicated that divorced, separated, or widowed indvidiuals tend to lack social support $(75,77,78)$, suffer from mental distress $(77,79$, 80 ), loneliness and isolation (81), which in its turn can highly contribute to increased alcohol consumption and psychological distress $(81,82)$.

The etiology and treatment of concurrent mental health and alcohol use problems are typically more complex than either alcohol use or mental health disorders alone (33). Effective screening and early intervention are predicated on the ability to identify the populations at increased risk for concurrent disorders. Our findings indicate that population-based initiatives designed to allocate greater resources and awareness to health and gender inequities and that target the subpopulations identified would be helpful to informing the development of primary and secondary prevention and treatment programs that adopt a concurrent disorders framework. This can be done by removing barriers so that everyone including vulnerable populations, have an equal opportunity to access resources especially for clinical diagnoses and treatment options. Increasing resources for mental health treatment sessions including telehealth, and tele-mental health, especially during confinement periods, has been noted to be a promising, appropriate and feasible approach for providing mental health support during the COVID-19 pandemic (83).

Additionally, telehealth can be used to provide resources for alcohol counseling and addiction treatment, and to follow up closely with patients and give them $24 / 7$ access to care (84). But, according to recent reports (85), a lot of work is needed to support large-scale dissemination and implementation through a multisectoral approach that has the capacity to respond to social needs, mobilize community social capital $(8,86)$, and provide training to social and health care providers on substance use and mental health disorders (8). These approaches can reduce health, economic and social inequity (87) that exacerbate mental illness (7) and alcohol consumption (88).

This study has several limitations. First, the study's crosssectional nature with self-reported responses prohibited the determination of any causal relationship between substance use and emotional distress with COVID-19 risk factors. Second, response bias might have occurred from the self-reported answers. Third, survey questions were only accessible for those who have access to electronic devices and the internet, limiting the generalizability of findings. Also, this secondary data analysis was restricted to the current risk factors and questions on frequency of alcohol intake, therefore, we could not capture additional modifiable risk and protective factors associated with changes in alcohol intake, patterns of use and associated impairment, and mental health. Furthermore, future longitudinal analyses will provide a greater understanding of directionality of the observed associations, along with potentially identifying factors that mediate or moderate these associations.

\section{CONCLUSION}

Our results indicate that symptoms of concurrent mental distress and alcohol use are a serious concern during the pandemic, and women and older adults, divorced, separated, or widowed, and individuals with financial worries, COVIDillness worries, and higher income groups appear to be at highest risk. As the pandemic continues to evolve, further research evaluating risk and protective factors and the long-term impact that COVID-19 has on mental health and alcohol intake is warranted to inform treatment and prevention strategies.

\section{DATA AVAILABILITY STATEMENT}

Publicly available datasets were analyzed in this study. This data can be found here: http://www.delvinia.com/solutions/ askingcanadians.

\section{ETHICS STATEMENT}

The studies involving human participants were reviewed and approved by Research Ethics Board at the Centre for Addiction and Mental Health and Research Ethics Boards of the Children's Hospital of Eastern Ontario (CHEO). The patients/participants 
provided their written informed consent to participate in this study.

\section{AUTHOR CONTRIBUTIONS}

FM: conceptualization, methodology, analysis, writing, review, and editing. HS-K: methodology, analysis, and review. BH: methodology and analysis. KC and $\mathrm{HH}$ : writing, review, and editing. GG: conceptualization, methodology, writing, review

\section{REFERENCES}

1. Fong MW, Gao H, Wong JY, Xiao J, Shiu EYC, Ryu S, et al. Non-pharmaceutical measures for pandemic influenza in non-healthcare settings-social distancing measures. Emerg Infect Dis. (2020) 26:97684. doi: 10.3201/eid2605.190995

2. Lazarus RS, Folkman S. Stress, Appraisal, and Coping. New York, NY: Springer Publishing Company (1984) p. 460.

3. Czeisler MÉ. Mental health, substance use, and suicidal ideation during the COVID-19 pandemic - United States, June 24-30, 2020. MMWR Morb Mortal Wkly Rep. (2020) 69:1049-57. doi: 10.15585/mmwr.mm6932al

4. Davillas A, Jones AM. The COVID-19 pandemic and its impact on inequality of opportunity in psychological distress in the UK. SSRN Electron J. (2020). 24. doi: $10.2139 / \mathrm{ssrn} .3614940$

5. Pedraza P de, Guzi M, Tijdens K, European Commission, Joint Research Centre. Life Dissatisfaction and Anxiety in COVID-19 Pandemic. (2020). Available online at: https://op.europa.eu/publication/manifestation identifier/PUB_KJNA30243ENN (accessed August 12, 2020).

6. Tubadji A, Webber D, Boy F. COVID-19: Narrative Economics, Public Policy, and Mental Health. (2020). Available online at: https:/voxeu.org/article/ covid-19-narrative-economics-public-policy-and-mental-health (accessed August 12, 2020).

7. Canadian Centre on Substance Use and Addiction. Boredom and Stress Drives Increased Alcohol Consumption during COVID-19: NANOS Poll Summary Report. (2020).p. 70.

8. Jemberie WB, Stewart Williams J, Eriksson M, Grönlund A-S, Ng N, Blom Nilsson M, et al. Substance use disorders and COVID-19: multi-faceted problems which require multi-pronged solutions. Front Psychiatry. (2020) 11:714. doi: 10.3389/fpsyt.2020.00714

9. Pollard MS, Tucker JS, Green HD Jr. Changes in adult alcohol use consequences during the COVID-19 pandemic in the US. JAMA Netw Open. (2020) 3:e2022942. doi: 10.1001/jamanetworkopen.2020.22942

10. Eckardt MJ, File SE, Gessa GL, Grant KA, Guerri C, Hoffman PL, et al. Effects of moderate alcohol consumption on the central nervous system. Alcohol Clin Exp Res. (1998) 22:998-1040. doi: 10.1111/j.1530-0277.1998.tb03695.x

11. Keyes KM, Hatzenbuehler ML, Hasin DS. Stressful life experiences, alcohol consumption, and alcohol use disorders: the epidemiologic evidence for four main types of stressors. Psychopharmacology. (2011) 218:117. doi: 10.1007/s00213-011-2236-1

12. Akerlind I, Hörnquist JO. Loneliness and alcohol abuse: a review of evidences of an interplay. Soc Sci Med. (1992) 34:405-14. doi: 10.1016/0277-9536(92)90300-F

13. Barrick C, Connors GJ. Relapse prevention and maintaining abstinence in older adults with alcohol-use disorders. Drugs Aging. (2002) 19:58394. doi: 10.2165/00002512-200219080-00004

14. Leigh-Hunt N, Bagguley D, Bash K, Turner V, Turnbull S, Valtorta $\mathrm{N}$, et al. An overview of systematic reviews on the public health consequences of social isolation and loneliness. Public Health. (2017) 152:15771. doi: 10.1016/j.puhe.2017.07.035

15. Sarkar D, Jung M, Wang J. Alcohol and the immune system. Alcohol Res. (2015) 37:153-5.

16. Szabo G, Mandrekar P. A recent perspective on alcohol, immunity, and host defense. Alcohol Clin Exp Res. (2009) 33:220-32. doi: 10.1111/j.1530-0277.2008.00842.x and editing. All authors contributed to the article and approved the submitted version.

\section{ACKNOWLEDGMENTS}

We are grateful to Methodify by Delvinia Inc. for providing inkind support for the survey data collection and making these data available. Data are publicly available for download at http://www. delvinia.com/coronavirus/.3.

17. Simet SM, Sisson J. Alcohol's effects on lung health and immunity. Alcohol Res. (2015) 37:199-208.

18. Szabo G, Saha B. Alcohol's effect on host defense. Alcohol Res. (2015) 37:15970 .

19. Gacouin A, Painvin B, Coirier V, Quelven Q, Delange B, Joussellin V, et al. Impact on ICU mortality of moderate alcohol consumption in patients admitted with infection. J Crit Care. (2020) 57:91-6. doi: 10.1016/j.jcrc.2020.02.008

20. Kim BJ, Kim BS, Kang JH. Alcohol consumption and incidence of metabolic syndrome in Korean men. A 3-year follow-up study. Circ J. (2012) 76:236371. doi: 10.1253/circj.CJ-12-0315

21. Corrao G, Rubbiati L, Bagnardi V, Zambon A, Poikolainen K. Alcohol and coronary heart disease: a meta-analysis. Addiction. (2000) 95:150523. doi: 10.1046/j.1360-0443.2000.951015056.x

22. Patra J, Taylor B, Irving H, Roerecke M, Baliunas D, Mohapatra S, et al. Alcohol consumption and the risk of morbidity and mortality for different stroke types-a systematic review and meta-analysis. BMC Public Health. (2010) 10:258. doi: 10.1186/1471-2458-10-258

23. Roerecke M, Rehm J. Irregular heavy drinking occasions and risk of ischemic heart disease: a systematic review and meta-analysis. Am J Epidemiol. (2010) 171:633-44. doi: 10.1093/aje/kwp451

24. Sachdeva A, Chandra M, Choudhary M, Dayal P, Anand KS. Alcohol-related dementia and neurocognitive impairment: a review study. Int J High Risk Behav Addict. (2016) 5:e27976. doi: 10.5812/ijhrba.27976

25. Kessler RC, Crum RM, Warner LA, Nelson CB, Schulenberg J, Anthony JC. Lifetime co-occurrence of DSM-III-R alcohol abuse and dependence with other psychiatric disorders in the National Comorbidity Survey. Arch Gen Psychiatry. (1997) 54:313-21. doi: 10.1001/archpsyc.1997.01830160031005

26. Xi B, Veeranki SP, Zhao M, Ma C, Yan Y, Mi J. Relationship of alcohol consumption to all-cause, cardiovascular, and cancer-related mortality in U.S. Adults. J Am Coll Cardiol. (2017) 70:913-22. doi: 10.1016/j.jacc.2017.06.054

27. Skinner WJW, O'Grady CP, Bartha C, Parker C. Concurrent Substance Use and Mental Health Disorders an Information Guide. Toronto: Centre for Addiction and Mental Health (2004). p. 60.

28. Antai-Otong D, Theis K, Patrick DD. Dual diagnosis: coexisting substance use disorders and psychiatric disorders. Nurs Clin North Am. (2016) 51:23747. doi: 10.1016/j.cnur.2016.01.007

29. Carrà G, Bartoli F, Brambilla G, Crocamo C, Clerici M. Comorbid addiction and major mental illness in Europe: a narrative review. Subst Abus. (2015) 36:75-81. doi: 10.1080/08897077.2014.960551

30. Lambert-Harris C, Saunders EC, McGovern MP, Xie H. Organizational capacity to address co-occurring substance use and psychiatric disorders: assessing variation by level of care. J Addict Med. (2013) 7:25-32. doi: 10.1097/ADM.0b013e318276e7a4

31. Fleury M-J, Grenier G, Bamvita J-M, Caron J. Profiles associated respectively with substance dependence only, mental disorders only and co-occurring disorders. Psychiatr Q. (2015) 86:355-71. doi: 10.1007/s11126-014-9335-1

32. Urbanoski KA, Cairney J, Bassani DG, Rush BR. Perceived unmet need for mental health care for Canadians with co-occurring mental and substance use disorders. Psychiatr Serv. (2008) 59:283-9. doi: 10.1176/ps.2008.59.3.283

33. Canadian Centre on Substance Abuse. Substance Abuse in Canada: Concurrent Disorders. Ottawa, Ont.: Canadian Centre on Substance Abuse (2009). Available online at: https://www.deslibris.ca/ID/223020 (accessed October 22, 2020). 
34. Canadian Institute for Health Information. Hospital Mental Health Services for Concurrent Mental Illness and Substance Use Disorders in Canada. Ottawa: Canadian Institute for Health Information (2013). Available online at: https:// secure.cihi.ca/free_products/MH\%20Concurrent\%20Disorders\%20AiBENweb.pdf (accessed October 22, 2020).

35. National Treatment Strategy Working Group. A Systems Approach to Substance Use in Canada: Recommendations for a National Treatment Strategy. Ottawa: National Framework for Action to Reduce the Harms Associated with Alcohol and Other Drugs and Substances in Canada (2008).

36. Department of Health UK. Mental Health Policy Implementation Guide: Dual Diagnosis Good Practice Guide | The Homeless Hub. (2002). Available online at: https://www.homelesshub.ca/resource/mental-healthpolicy-implementation-guide-dual-diagnosis-good-practice-guide (accessed November 20, 2020).

37. Victoria's Hub for Health Services \& Business, Victoria State Government (Australia). Dual Diagnosis. (2013). Available online at: http://www2.health. vic.gov.au/mental-health/practice-and-service-quality/specialist-responses/ dual-diagnosis (accessed November 20, 2020).

38. Chiappini S, Guirguis A, John A, Corkery JM, Schifano F. COVID-19: the hidden impact on mental health and drug addiction. Front Psychiatry. (2020) 11:767. doi: $10.3389 /$ fpsyt.2020.00767

39. Sher L. Dual disorders and suicide during and following the COVID-19 pandemic. Acta Neuropsychiatr. (2020) 33:49-50. doi: 10.1017/neu.2020.37

40. Radloff LS. The CES-D Scale: A Self-Report Depression Scale for Research in the General Population. (1977). Available online at: http://conservancy.umn.edu/ handle/11299/98561 (accessed April 23, 2020).

41. Spitzer RL, Kroenke K, Williams JBW, Löwe B. A brief measure for assessing generalized anxiety disorder: the GAD-7. Arch Intern Med. (2006) 166:10927. doi: 10.1001/archinte.166.10.1092

42. Kroenke K, Spitzer RL, Williams JBW, Monahan PO, Löwe B. Anxiety disorders in primary care: prevalence, impairment, comorbidity, and detection. Ann Intern Med. (2007) 146:31725. doi: 10.7326/0003-4819-146-5-200703060-00004

43. Ettman C, Abdalla S, Cohen G, Sampson L, Vivier P, Galea S. Prevalence of depression symptoms in US adults before and during the COVID-19 pandemic. JAMA Network Open. (2020) 3:e2019686. doi: 10.1001/jamanetworkopen.2020.19686

44. Salari N, Hosseinian-Far A, Jalali R, Vaisi-Raygani A, Rasoulpoor S, Mohammadi M, et al. Prevalence of stress, anxiety, depression among the general population during the COVID-19 pandemic: a systematic review and meta-analysis. Global Health. (2020) 16:57. doi: 10.1186/s12992-020-00589-w

45. José BS, van Oers HA, van de Mheen HD, Garretsen HF, Mackenbach JP. Stressors and alcohol consumption. Alcohol Alcohol. (2000) 35:30712. doi: 10.1093/alcalc/35.3.307

46. Uhart M, Wand GS. Stress, alcohol, and drug interaction: an update of human research. Addict Biol. (2009) 14:43-64. doi: 10.1111/j.1369-1600.2008.00131.x

47. Bailey P, Purcell S, Calvar J, Baverstock A. Diet \& health under COVID-19. (2021). Available from: https://www.ipsos.com/sites/default/files/ct/news/ documents/2021-01/uk_combined_charts_fats_sugar_-_updated_ab_-_10_ dec_2020_-_q1-q4c_0.pdf (accessed Febraury 11, 2021).

48. Daly M, Robinson E. Problem drinking before and during the COVID-19 crisis in US and UK adults: evidence from two population-based longitudinal studies. medRxiv [Preprint]. (2020). doi: 10.1101/2020.06.25.20139022

49. Garnett C, Jackson S, Oldham M, Brown J, Steptoe A, Fancourt D. Factors associated with drinking behaviour during COVID-19 social distancing and lockdown among adults in the UK. Drug Alcohol Depend. (2021) 219:108461. doi: 10.1016/j.drugalcdep.2020.108461

50. Portman Group. YouGov-Portman-Group-Survey-on-Alcohol-ConsumptionDuring-the-COVID-19-lockdown-2.pdf. (2020). Available online at: https:// 1kp8gk3a0fdl3qf9kb2wo9ei-wpengine.netdna-ssl.com/wp-content/uploads/ 2020/06/YouGov-Portman-Group-survey-on-alcohol-consumptionduring-the-COVID-19-lockdown-2.pdf (accessed Febraury 9, 2021).

51. Weerakoon SM, Jetelina KK, Knell G. Longer time spent at home during COVID-19 pandemic is associated with binge drinking among US adults. Am J Drug Alcohol Abuse. (2020) 47:98-106. doi: 10.1080/00952990.2020. 1832508

52. Bickel WK, Johnson MW, Koffarnus MN, MacKillop J, Murphy JG. The behavioral economics of substance use disorders: reinforcement pathologies and their repair. Annu Rev Clin Psychol. (2014) 10:64177. doi: 10.1146/annurev-clinpsy-032813-153724

53. Rachlin H, Battalio R, Kagel J, Green L. Maximization theory in behavioral psychology. Behav Brain Sci. (1981) 4:37188. doi: 10.1017/S0140525X00009407

54. Murphy JG, MacKillop J. Relative reinforcing efficacy of alcohol among college student drinkers. Exp Clin Psychopharmacol. (2006) 14:21927. doi: 10.1037/1064-1297.14.2.219

55. González-Sanguino C, Ausín B, Castellanos MÁ, Saiz J, López-Gómez A, Ugidos C, et al. Mental health consequences during the initial stage of the 2020 Coronavirus pandemic (COVID-19) in Spain. Brain Behav Immun. (2020) 87:172-6. doi: 10.1016/j.bbi.2020.05.040

56. Klaiber P, Wen JH, DeLongis A, Sin NL. The ups and downs of daily life during COVID-19: age differences in affect, stress, and positive events. J Gerontol B Psychol Sci Soc Sci. (2020) 76:e30-7. doi: 10.1093/geronb/gbaa096

57. Canadian Centre on Substance Abuse. Alcohol Consumption During COVID19. (2020).

58. Laird KT, Krause B, Funes C, Lavretsky H. Psychobiological factors of resilience and depression in late life. Transl Psychiatry. (2019) 9:118. doi: 10.1038/s41398-019-0424-7

59. Lee EE, Bangen KJ, Avanzino JA, Hou B, Ramsey M, Eglit G, et al. Outcomes of randomized clinical trials of interventions to enhance social, emotional, and spiritual components of wisdom: a systematic review and meta-analysis. JAMA Psychiatry. (2020) 77:925-35. doi: 10.1001/jamapsychiatry.2020.0821

60. Wang C, Pan R, Wan X, Tan Y, Xu L, Ho CS, et al. immediate psychological responses and associated factors during the initial stage of the 2019 Coronavirus Disease (COVID-19) epidemic among the general population in China. Int J Environ Res Public Health. (2020) 17:1729. doi: 10.3390/ijerph17051729

61. Viertiö S, Kiviruusu O, Piirtola M, Kaprio J, Korhonen T, Marttunen M, et al. Factors contributing to psychological distress in the working population, with a special reference to gender difference. BMC Public Health. (2021) 21:611. doi: 10.1186/s12889-021-10560-y

62. Rodriguez L, Litt D, Stewart S. Drinking to cope with the pandemic: the unique associations of COVID-19-related perceived threat and psychological distress to drinking behaviors in american men and women. Addict Behav. (2020) 110:106532. doi: 10.1016/j.addbeh.2020.106532

63. McGinty EE, Presskreischer R, Han H, Barry CL. Psychological distress and loneliness reported by US adults in 2018 and April (2020). JAMA. (2020) 324:93-4. doi: 10.1001/jama.2020.9740

64. Pierce M, Hope H, Ford T, Hatch S, Hotopf M, John A, et al. Mental health before and during the COVID-19 pandemic: a longitudinal probability sample survey of the UK population. Lancet Psychiatry. (2020) 7:88392. doi: 10.1016/S2215-0366(20)30308-4

65. Farré L, Fawaz Y, González L, Graves J. How the COVID-19 Lockdown Affected Gender Inequality in Paid and Unpaid Work in Spain. Social Sciences (2020). p. 39.

66. Power K. The COVID-19 pandemic has increased the care burden of women and families. Sustainabil Sci Pract Pol. (2020) 16:67-73. doi: 10.1080/15487733.2020.1776561

67. Ahmed MZ, Ahmed O, Aibao Z, Hanbin S, Siyu L, Ahmad A. Epidemic of COVID-19 in China and associated psychological problems. Asian J Psychiatr. (2020) 51:102092. doi: 10.1016/j.ajp.2020.102092

68. Newby JM, O’Moore K, Tang S, Christensen H, Faasse K. Acute mental health responses during the COVID-19 pandemic in Australia. PLoS ONE. (2020) 15:e0236562. doi: 10.1371/journal.pone.0236562

69. Sidor A, Rzymski P. Dietary choices and habits during COVID-19 lockdown: experience from Poland. Nutrients. (2020) 12:1657. doi: 10.3390/nu12061657

70. Grant BF, Chou SP, Saha TD, Pickering RP, Kerridge BT, Ruan WJ, et al. Prevalence of 12-month alcohol use, high-risk drinking, and DSM-IV alcohol use disorder in the United States, 2001-2002 to 2012-2013: results from the national epidemiologic survey on alcohol and related conditions. JAMA Psychiatry. (2017) 74:911-23. doi: 10.1001/jamapsychiatry.2017.2161

71. Peltier MR, Verplaetse TL, Mineur YS, Petrakis IL, Cosgrove KP, Picciotto MR, et al. Sex differences in stress-related alcohol use. Neurobiol Stress. (2019) 10:100149. doi: 10.1016/j.ynstr.2019.100149

72. Seedat S, Scott KM, Angermeyer MC, Berglund P, Bromet EJ, Brugha TS, et al. Cross-national associations between gender and mental disorders in 
the World Health Organization World Mental Health Surveys. Arch Gen Psychiatry. (2009) 66:785-95. doi: 10.1001/archgenpsychiatry.2009.36

73. Bond JC, Roberts SCM, Greenfield TK, Korcha R, Ye Y, Nayak MB, Gender differences in public and private drinking contexts: a multilevel GENACIS analysis. Int J Environ Res Public Health. (2010) 7:213660. doi: 10.3390/ijerph7052136

74. Ben-Zur H. Loneliness, optimism, and well-being among married, divorced, and widowed individuals. J Psychol. (2012) 146:23-36. doi: 10.1080/00223980.2010.548414

75. Scott KM, Wells JE, Angermeyer M, Brugha TS, Bromet E, Demyttenaere $\mathrm{K}$, et al. Gender and the relationship between marital status and first onset of mood, anxiety and substance use disorders. Psychol Med. (2010) 40:1495505. doi: $10.1017 /$ S0033291709991942

76. Hasin DS, Stinson FS, Ogburn E, Grant BF. Prevalence, correlates, disability, and comorbidity of DSM-IV alcohol abuse and dependence in the United States: results from the national epidemiologic survey on alcohol and related conditions. Arch Gen Psychiatry. (2007) 64:83042. doi: 10.1001/archpsyc.64.7.830

77. Gähler M. "To Divorce Is to Die a Bit.:" A Longitudinal Study of Marital Disruption and Psychological Distress Among Swedish Women and Men. Fam J. (2006) 14:372-82. doi: 10.1177/1066480706290145

78. Vaingankar JA, Abdin E, Chong SA, Shafie S, Sambasivam R, Zhang YJ, et al. The association of mental disorders with perceived social support, and the role of marital status: results from a national cross-sectional survey. Arch of Public Health. (2020) 78:108. doi: 10.1186/s13690-020-00476-1

79. Kendler KS, Hettema JM, Butera F, Gardner CO, Prescott CA. Life event dimensions of loss, humiliation, entrapment, and danger in the prediction of onsets of major depression and generalized anxiety. Arch Gen Psychiatry. (2003) 60:789-96. doi: 10.1001/archpsyc.60.8.789

80. Aye WT, Lien L, Stigum H, Win HH, Oo T, Bjertness E. The prevalence of mental distress and the association with education: a cross-sectional study of 18-49-year-old citizens of Yangon Region, Myanmar. BMC Public Health. (2020) 20:94. doi: 10.1186/s12889-020-8209-8

81. Stickley A, Koyanagi A, Roberts B, Richardson E, Abbott P, Tumanov S, et al. Loneliness: its correlates and association with health behaviours and outcomes in nine countries of the former Soviet Union. PLoS ONE. (2013) 8:e67978. doi: 10.1371/journal.pone.0067978
82. Santini ZI, Jose PE, Cornwell EY, Koyanagi A, Nielsen L, Hinrichsen C, et al. Social disconnectedness, perceived isolation, and symptoms of depression and anxiety among older Americans (NSHAP): a longitudinal mediation analysis. Lancet Public Health. (2020) 5:e62-70. doi: 10.1016/S2468-2667(19) 30230-0

83. Di Carlo F, Sociali A, Picutti E, Pettorruso M, Vellante F, Verrastro V, et al. Telepsychiatry and other cutting edge technologies in Covid-19 pandemic: bridging the distance in mental health assistance. Int J Clin Pract. (2020) 75:e13716. doi: 10.22541/au.159007666.69069059

84. Hollander JE, Carr BG. Virtually perfect? Telemedicine for Covid-19. N Engl J Med. (2020) 382:1679-81. doi: 10.1056/NEJMp2003539

85. Lin L, Fernandez A, Bonar E. Telehealth for substance-using populations in the age of coronavirus disease 2019: recommendations to enhance adoption. JAMA Psychiatry. (2020) 77:1209-10. doi: 10.1001/jamapsychiatry.2020.1698

86. Fantuzzi C, Mezzina R. Dual diagnosis: a systematic review of the organization of community health services. Int J Soc Psychiatry. (2020) 66:300-10. doi: 10.1177/0020764019899975

87. Singu S, Acharya A, Challagundla K, Byrareddy SN. Impact of social determinants of health on the emerging COVID19 pandemic in the United States. Front Public Health. (2020) 8:406. doi: 10.3389/fpubh.2020.00406

88. Debopadhaya S, Sprague AD, Mou H, Benavides TL, Ahn SM, Reschke CA, et al. Social determinants associated with COVID-19 mortality in the United States. medRxiv [Preprint]. (2020). doi: 10.1101/2020.08.28. 20183848

Conflict of Interest: The authors declare that the research was conducted in the absence of any commercial or financial relationships that could be construed as a potential conflict of interest.

Copyright (๑) 2021 Mougharbel, Sampasa-Kanyinga, Heidinger, Corace, Hamilton and Goldfield. This is an open-access article distributed under the terms of the Creative Commons Attribution License (CC BY). The use, distribution or reproduction in other forums is permitted, provided the original author(s) and the copyright owner(s) are credited and that the original publication in this journal is cited, in accordance with accepted academic practice. No use, distribution or reproduction is permitted which does not comply with these terms. 